\title{
Rheumatoid arthritis in Lesotho
}

\author{
J. D. MOOLENBURGH, ${ }^{*}$ S. MOORE, H.A. VALKENBURG, AND \\ M. G. ERASMUS
}

From the Scott Hospital, Morija, Lesotho, and the Department of Epidemiology, Erasmus University, Rotterdam, Holland

SUMmARY Thirty-nine black African patients were seen with probable, definite or classical rhe umatoid arthritis (RA); 32 of these were seen in a prospective study out of a total of 15834 new patients 15 years and older at presentation seen in a 12-month period. The diagnosis was based on the American Rheumatism Association criteria for RA or the Rome criteria for inactive RA. The high incidence of severe disease as well as the occurrence of advanced disease in young patients is notable. $80 \%$ of the patients came from rural areas. Radiological lesions were found in $74 \%$ and serological abnormalities in $92 \%$. Rheumatoid factor (RF) was found to be positive in $12 \%$ of an age and sex matched control group and in $19 \%$ of a group of patients suffering from tuberculosis.

Epidemiological studies of the pattern of rheumatoid arthritis (RA) in black Africans point to a lower prevalence as well as a milder form of the disease than in Western European and Northern American populations. ${ }^{12}$ Solomon et al. ${ }^{3}$ however, observed that in urbanised African Negros the prevalence of RA approached that normally encountered in Western Europe, while the disease was very rare in rural Africans. ${ }^{4}$ From hospital studies others ${ }^{5}$ have commented on the mildness of the disease in Africans.

Little is known about the manner in which RA is influenced or modified by environmental, cultural, and genetic factors in different populations. Reports from various populations are therefore important, as has been pointed out by Beighton et al. ${ }^{4}$ In this paper the results of a prospective survey of a hospital population, mostly of the rural areas of Lesotho, are presented.

DEMOG RA P H Y

Lesotho is a black African state, which received its independence from the British Government in 1966. It lies in the southern hemisphere on the continent of Africa between $28^{\circ}$ and $31^{\circ}$ south and between $27^{\circ}$ and $30^{\circ}$ east. It therefore lies outside the tropics, and

Accepted for publication 26 January 1983.

* Present address: Diaconessen Hospital, Voorburg, Holland.

Correspondence to $\mathrm{Dr}$ J. D. Moolenburgh, Department of Epidemiology, Erasmus University Medical Faculty, PO Box 1738, 3000 DR Rotterdam, the Netherlands. all its land is more than 1000 metres above sea level. It ranks among the 25 poorest nations on earth according to the UN classification. Much of its male population finds employment in the mining industry of the Republic of South Africa as migrant workers. Most of the country is rural and only in and around its capital Maseru do periurban conditions exist, comprising $4 \cdot 3 \%$ of the total population. ${ }^{7}$ Average daily temperatures vary in the lowlands from $24^{\circ} \mathrm{C}$ in January to $8^{\circ} \mathrm{C}$ in June and July. During winter nights temperatures can drop as low as $-10^{\circ} \mathrm{C}$ in the lowlands and $-20^{\circ} \mathrm{C}$ in the mountains. Air frost is experienced for up to 80 days per year in the lowlands and for most of the year in the mountains. Mean annual rainfall is low and amounts to between 700 and $800 \mathrm{~mm}$ in most parts of the lowlands. Of the annual rainfall $85 \%$ occurs in the 7 months from October to April.

THE PEOPLE

In 1976 the total number of Basutho (that is, inhabitants of Lesotho) was slightly more than 1.2 million. As the approximate growth is $2.3 \%$ per year, this number will be considerably more by now. Typically for an African population the younger age groups are over-represented. About $40 \%$ of the population is under 15 years and only $4 \%$ is over the age of 65 . Around $75 \%$ of the Basutho live in the lower areas, which comprise $25 \%$ of the country, giving these areas one of the highest rural population densities in Africa. Above 15 years of age males represent only 


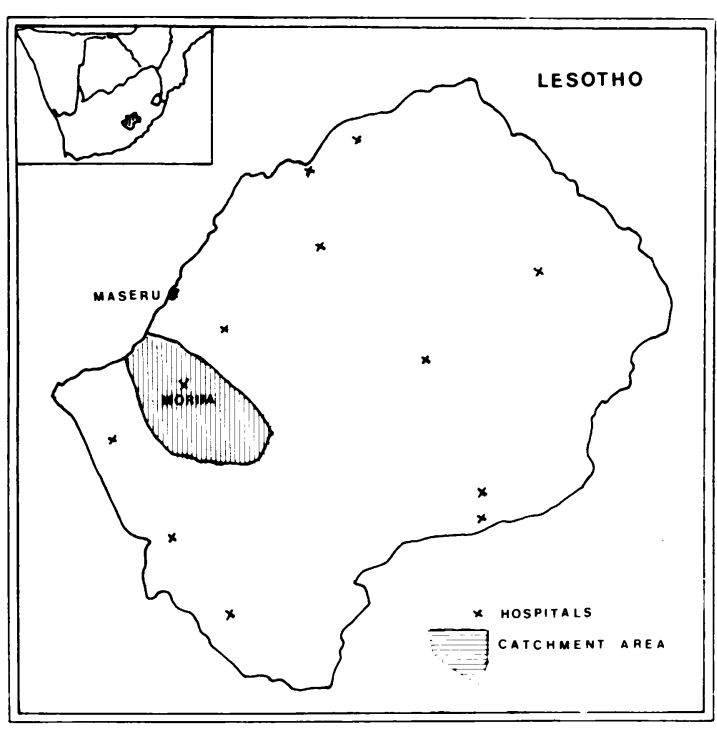

Fig. 1 Map of Lesotho.

$37 \%$ of the resident population. The others work for most of the year as migrant workers in the Republic of South Africa, mainly in the mines. The major health problems are tuberculosis, venereal diseases, gastroenteritis, and typhoid fever.

The genetic differences between the 4 major groups of the Negro races of southern Africa, namely, the Sotho, Tswana, Xhosa, and Zulu, are relatively small. Of these the Sotho people have a common historical root with the Tswana.

Scott Hospital is one of the 13 major general hospitals in Lesotho (Fig. 1). It is a church-related institution, which has offered good medical care for 45 years. It is situated at an altitude of $1700 \mathrm{~m}$ about 40 $\mathrm{km}$ south of the capital Maseru. About two-thirds of its patients are drawn from approximately 100000 persons in surrounding area. The remainder come from further away, but not for reasons of specialised care, as the hospitals are equally distributed over the country.

\section{Patients and methods}

For a period of one year a prospective study was conducted starting on 1 May 1980. In addition patients were screened for rheumatic conditions in the 6 months following this period. All outpatients who come to Scott Hospital are seen by a doctor. Any patients presenting with joint complaints suggestive of RA were referred to one of the 2 doctors (J.D.M. and S.M.) conducting the survey.

A detailed history was then taken including present address, past addresses with particular reference to any period of stay in areas that were considered to be urban (cities, mines), age, amount and source of income, social position, and onset and course of the disease. Patients were arbitrarily classified as urban if they had lived in an urbanised area for more than 5 years or if their disease had started there.

The patients were photographed and a careful joint examination was performed and recorded on a specially prepared form. Radiographs of hands and feet were taken routinely and each patient had blood drawn for assessment of rhe umatoid factor (RF) by means of the latex fixation method (RheumaWellcotest, without titration).

For each patient with RA three age and sex matched patients with minor nonrheumatic complaints were selected. Rheumatoid factor (RF) and VDRL were assessed in the controls. RF was determined also in a second control group of 47 more or less age and sex matched patients suffering from tuberculosis. The radiographs were read independently by H.A.V. and M.G.E.

The presence of active RA was defined by applying the original ARA criteria. ${ }^{8}$ For the presence of inactive RA the modified Rome criteria were used, as in previous studies in South Africa. ${ }^{23}$

\section{Results}

During the prospective study period 15834 new patients aged 15 years or older were seen in the outpatient department; 10371 , or $65.5 \%$ of them, came from the Scott Hospital catchment area. The male/female ratio of the general outpatients seen was $1: 3$ and $22 \%$ were over the age of 44 years. Only $5 \%$ of the patients came for diseases of the musculoskeletal system and about $2 \%$ for venereal diseases. The 3 major conditions for which the patients sought help were diseases of the genitourinary system, pregnancy, and injuries, totalling $50 \%$ of all conditions. Thirty-two patients with probable, definite, or classical RA were seen during this prospective period. An additional 7 patients were observed in the subsequent half year; 2 of these had already been seen during the period of the prospective study, but, although clinically suspected of suffering from early RA, they did not at that stage meet the criteria. Twenty-four or $75 \%$ of the patients came from inside the hospital catchment area as opposed to two-thirds of the total group of outpatients. Six came from outside, and the source of 2 was unknown.

The youngest patient was a girl of 17 (onset at the age of 15) with classical RA and deformities of the hands already present. The oldest patient was a man of 85 years. The age and sex specific rates per 1000 for RA are presented in Table 1 . The rate in males 
Table 1 Age specific prevalence of combined probable, definite, and classical rheumatoid arthritis

\begin{tabular}{lrcll}
\hline $\begin{array}{l}\text { Age } \\
\text { group }\end{array}$ & $\begin{array}{l}\text { Total } \\
\text { number }\end{array}$ & $\begin{array}{l}\text { Relative } \\
\text { percentage }\end{array}$ & $\begin{array}{l}\text { Affected } \\
\text { by RA }\end{array}$ & $\begin{array}{l}\text { Rate } \\
\text { per } 1000\end{array}$ \\
\hline $15-24$ & 5046 & $31 \cdot 9$ & 2 & $0 \cdot 4(0 \cdot 2)^{*}$ \\
$25-34$ & 4698 & $29 \cdot 7$ & 8 & $1 \cdot 7(0 \cdot 4)$ \\
$35-44$ & 2262 & $14 \cdot 3$ & 5 & $2 \cdot 2(0 \cdot 0)$ \\
$45-54$ & 1566 & $9 \cdot 9$ & 8 & $5 \cdot 1(0 \cdot 6)$ \\
$55-64$ & 1218 & $7 \cdot 7$ & 5 & $4 \cdot 1(1 \cdot 6)$ \\
$65+$ & 1044 & $6 \cdot 6$ & 4 & $3 \cdot 8(0 \cdot 0)$ \\
Total & 15834 & $100 \cdot 1$ & 32 & $2 \cdot 0(0 \cdot 4)$ \\
Males & 4050 & $25 \cdot 6$ & 10 & $2 \cdot 5(0 \cdot 5)$ \\
Females & 11784 & 74.4 & 22 & $1 \cdot 9(0 \cdot 3)$ \\
\hline
\end{tabular}

${ }^{*}$ Between brackets: rate of probable RA per 1000 .

was slightly higher than in females. Rates increased with age to level off after the age of 45 years.

Fourteen of all 39 patients seen with RA had lived in an urban environment at any stage of their life. Of these only 8 could be classified as being urban; 2 of them were graded as probable, 4 as definite, and 2 as classical. Of the 31 rural patients 6 were probable, 8 definite, and 17 classical.

Radiographs were taken from 38 patients. In 6 only films of the hands were obtained, in the others of both hands and feet. Erosive arthritis (EA) grade 2 or more was found in $28(74 \%)$ of them. Of the 28 patients with EA, $21(75 \%)$ had grade 3 to 4 . Of the 8 men with EA, only 1 had grade 2 , while of the 20 women 6 had grade 2 . This difference is not significant. The joints most frequently involved were the wrists and metacarpophalangeal (MCP) joints. RF was determined in the sera of 37 patients. Two patients, both female, one classified as definite and one as probable case, 'escaped' before blood could be taken. Only 3 of the 37 had a negative test; 2 were men classified as probable and one, a woman, classified as definite RA with grade 2 EA. The sera of 17 patients were checked in the laboratory of the Department of Epidemiology, Erasmus University, Rotterdam. In only one case was the result slightly different, but this serum showed a positive WaalerRose test. There was a high degree of concordance between the latex fixation test and the Waaler-Rose test in these 17 sera, all sera positive in the latex test being positive also in the Waaler-Rose test. In the control group a positive latex fixation test was found in $12 \%$ of the patients, all of them in the age group 35 years and older. A positive VDRL was found in $2 \%$, not correlating with the latex fixation test. In the second control group of patients with tuberculosis $19 \%$ gave a positive latex fixation test.

\section{EXTRA-ARTICULAR MANIFESTATIONS}

Subcutaneous nodules were noted in $9(24 \%)$ of the patients. Biopsies were taken in 7 cases, Histologically 5 of these fitted in with the diagnosis of a rheumatoid nodule, in one the diagnosis was equivocal, and one was a neurofibroma. All nodules except the neurofibroma were found in women. Three patients had keratoconjunctivitis sicca, and 2 complained about a dry mouth.

An attempt was made to see as many patients as possible at follow-up. On the average patients were seen 3 times in the $1 \frac{1}{2}$ years (range 1 to 8 times). Thirteen required admission to hospital and 3 of these required more than one admission. This means one admission for RA per 175 admissions.

\section{Discussion}

During the prospective study year 23 patients with definite or classical disease were seen from inside the hospital catchment area, as opposed to one with probable disease. Three-quarters of our patients had erosive arthritis and more than $20 \%$ had subcutaneous nodules. This ratio of severe to mild disease is much higher than seen in the urban South African population described by Solomon et al., ${ }^{3}$ where the number of cases found to belong to the probable category was up to 3 times as large as those with definite and classical disease. The clinical picture of our patients resembles that seen by Solomon $e^{a}$ al. $^{3}$

Table 2 The presence of erosive arthritis in males and females per diagnostic category

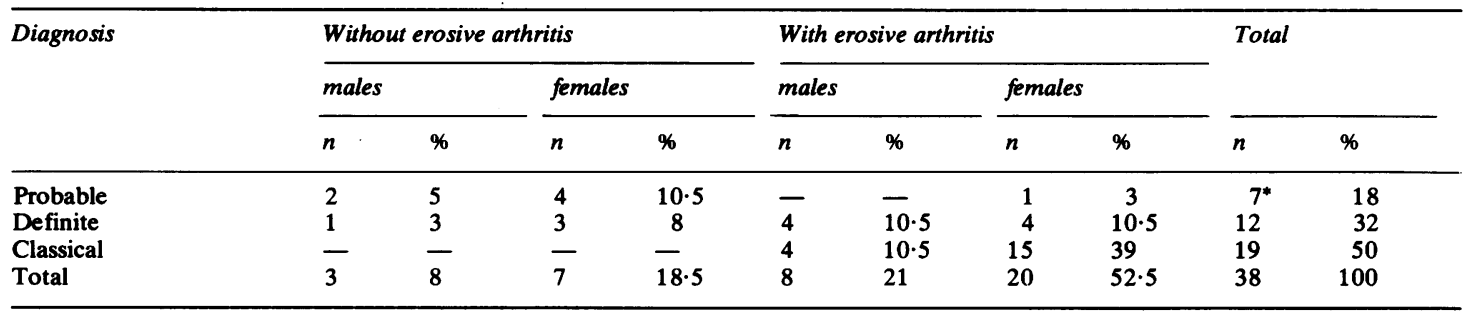

*One case of probable RA, a male, did not have $x$-rays taken. 
However, in their study only 2 out of 5 definite cases required admission to hospital. The 22 adult patients, on the assumption of a population denominator of 40000 people over 25 years old in the hospital catchment area and a hospital admission rate of $40 \%$, give a prevalence of definite and classical cases of 1.4 per 1000 . Inclusion of the probable category that can be expected at the population level, would give an estimated prevalence 4 to $7^{4}$ times as high, or 5.5 to $9 \cdot 6$ per 1000 . The latter figure comes close to the $1 \%$ rheumatoid arthritis found in temperate climates. ${ }^{9}$ However, this figure is probably still too low. In England and Wales ${ }^{10}$ and in Holland (unpublished results) $14-15 \%$ of all consultations in general practice were for rhe umatic complaints, while only $5 \%$ of the outpatients of the Scott Hospital came for conditions of the locomotor system. Furthermore, the transport facilities being what they are in a country like Lesotho, it is very difficult for people with severe joint disease to get to a hospital. This is exemplified by the fact that, while one-third of all outpatients came from outside the hospital catchment area, only one-quarter of the RA patients did so. In fact one woman in our area, who is not included in the survey and was seen by us during outstation visits was indeed so crippled by RA that she could not be moved at all.

Our study confirms the high prevalence of rheumatoid factor in black African populations. If we leave it out as a criterion for classification in the cases of active RA, one patient would change the classification from definite to probable and 2 from probable to possible. This is certainly not significant.

The question remains of how to explain the similarities between this study and the one in Johannesburg and the differences from studies among rural Africans. Similarities are the high altitude and hence the cold climate; but Lesotho is considerably colder. In both situations there is a lack of the parasitic diseases such as schistosomiasis, malaria, and filariasis, which are so characteristic of the rest of Africa. ${ }^{11}$ Prevalent diseases include tuberculosis and venereal diseases, partly because population densities are high. Other factors could be a corresponding genetic background and the high rate of inbreeding in Lesotho.

Lastly it should be mentioned that the low prevalence of RA in developing countries could be due to an excess mortality from infections in association with this disease,${ }^{12}$ particularly where health facilities are poor. A low prevalence observed in such countries could thus be explained by an excessive death rate of RA patients from parasitic and other infections and a rapid course of the disease. Indeed we failed to follow up a number of our seriously ill patients. As histories are so unrealiable in African populations, we cannot say anything definite about the duration of the disease, but we have certainly seen a number of serious cases that developed rapidly, also in young patients. To draw more meaningful conclusions one would need more insight in the prevalence of RA in the population of Lesotho. Recently, a combined epidemiological survey on tuberculosis and RA has been performed, the results of which we intend to publish in due course.

We gratefully acknowledge help and advice from the following people and institutions: Dr S. Brighton, HF Verwoerd Hospital, Pretoria; Professor O. L. Meyers and Dr E. Bateman, Groote Schuur Hospital, Cape Town; Dr T. Germond, Dr J. Schutz, Dr R. Verhage, and Dr A. Moore, medical officers, Scott Hospital; the Department of Pathology, Academic Hospital, Bloemfontein; Mr S. Davelaar, Miss C. M. Kuynders, and Mrs C. H. L. Valkenburg for their technical help.

\section{References}

1 Muller A S. Population studies on the prevalence of rheumatic diseases in Liberia and Nigeria. Leiden: MD Thesis, 1970.

2 Meyers O L, Daynes G, Beighton P. Rheumatoid arthritis in a tribal Xhosa population in the Transkei, Southem Africa. Ann Rheum Dis 1977; 36: 62-5.

3 Solomon L, Robin G, Valkenburg H A. Rheumatoid arthritis in an urban South African Negro population. Ann Rheum Dis 1975 ; 34: 128-35.

4 Beighton P, Solomon L, Valkenburg H A. Rheumatoid arthritis in a rural South African Negro population. Ann Rheum Dis 1975; 34: 136-41.

5 Greenwood B M. Polyarthritis in Western Nigeria. I. Rheumatoid arthritis. Ann Rheum Dis 1969; 28: 488-96.

6 Kanyerezi B R. Rheumatoid arthritis in Uganda. East Afr Med J 1969; 47: 71-5.

7 Lesotho Social Indicators Data Sheet. Annex I. 1981; 1.

8 Ropes M W, Bennet G A, Cobb S, Jacox R, Jessar R A. Ann Rheum Dis 1959; 18: 49-53.

9 Lawrence J S. Rheumatism in populations. London: Heinemann, 1977.

10 Logan W P D, Cushion A A. Morbidity statistics from general practice. General studies on medical and population subjects, no. 14. London: HMSO, 1958: 1.

11 Greenwood B M. Autoimmune disease and parasitic infections in Nigerians. Lancet 1968; ii: $380-2$.

12 Uddin J, Kraus A S, Kelly H G. Survivorship and death in rheumatoid arthritis. Arthritis Rheum 1970; 13: 125-30. 